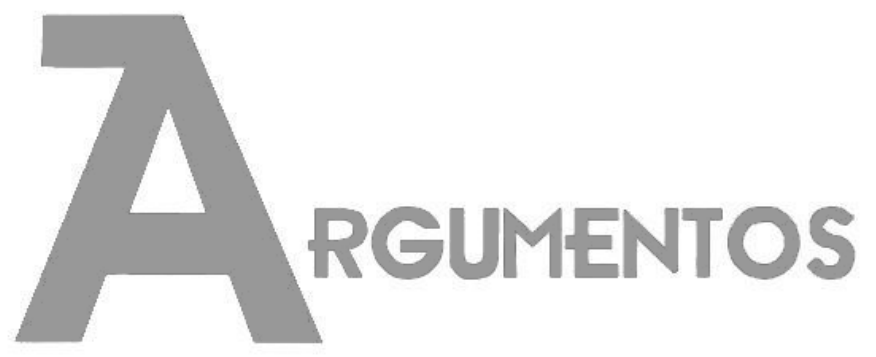

Vol. 18, n. 2, jul./dez. 2021 ISSN: 2527-2551 (online)

https://www.periodicos.unimontes.br/index.php/argumentos

\title{
Resenha
}

FRYDENBERG, Julio. Historia social del fútbol: del amateurismo a la profesionalización. 1a ed. Buenos Aires: Siglo Veintiuno Editores, 2011.

\section{As contribuições do livro Historia social del Fútbol: del amateurismo a la profesionalización para os estudos do futebol na América Latina}

Sarah Teixeira Soutto Mayor ${ }^{1}$

Recebido em: 01/04/2021

Aprovado em: 22/05/2021

Historia social del fútbol: del amateurismo a la profesionalización, escrito pelo historiador argentino Julio Frydenberg e publicado no ano de 2011 pela Siglo Veintiuno Editores, pode ser considerado um dos principais trabalhos dedicados à história do futebol na América Latina. Produto da tese de doutorado do autor, reúne vasto conjunto de fontes cuidadosamente analisadas, distanciando-se de modelos narrativos lineares e superficiais.

Frydenberg é doutor em História pela Universidade de Buenos Aires (UBA) e docente em duas instituições: a Universidade Nacional de San Martín (UNSAM) e a Universidade Nacional de La Plata (UNLP). É fundador e coordenador do Centro de Estudos do Esporte, da Escola de Política e Governo da UNSAM. Historia social del fútbol materializa-se, assim, como importante produto de sua rica experiência acadêmica,

\footnotetext{
1 Universidade Federal de Juiz de Fora, campus Governador Valadares, Brasil. Professora do Departamento de Educação Física. E- mail: sarahsoutto@gmail.com. ORCID: https://orcid.org/0000-00031643-6223.
} 
Dossiê | As contribuições do livro Historia social del Fútbol: del amateurismo a la profesionalización para os estudos do futebol na América Latina (MAYOR, Sarah Teixeira Soutto)

constituindo-se em leitura imprescindível para pesquisadores que se interessam pela história do futebol argentino e latino-americano.

Nas páginas do livro, o leitor não se depara apenas com informações sobre acontecimentos da seara esportiva, mas (e especialmente) com problematizações densas que reafirmam continuamente o futebol enquanto importante elemento de sociabilidade e de construção de identidades coletivas, o que perpassa tanto o sentido unificador da ideia de nação quanto os imaginários periféricos, díspares e conflituosos do imenso e tortuoso tecido urbano em formação. Como o próprio autor descreve, o futebol pode ser interpretado como um "ponto de cruzamento entre os âmbitos cotidianos da casa e das periferias e os grandes eventos domingueiros - quer dizer, entre o ordinário e habitual e o extraordinário ou ritual" (p.13).

Nessa empreitada, Frydenberg percorre com detalhamento e sensibilidade o cenário social, cultural e econômico da cidade de Buenos Aires, nas três primeiras décadas do século $X X$, localizando a emergência e o desenvolvimento do futebol em meio às próprias transformações da cidade. E ainda que destine a Buenos Aires o foco principal do estudo, tece relações com outras cidades argentinas e constrói diálogos com países europeus e latino-americanos que compartilhavam das ambiguidades do fenômeno futebolístico da época.

No início de sua escrita, o autor constata o pouco envolvimento do que ele denomina de "historiografia profissional" em pesquisas sobre o futebol na Argentina. No entanto, destaca a existência de trabalhos realizados por pesquisadores de outras áreas que apresentam aspectos valiosos sobre o passado do esporte no país. Eduardo Archetti, Ariel Scher, Héctor Palomino e Pablo Alabarces são exemplos citados por Frydenberg, que dedica especial atenção ao legado deixado pelo antropólogo Archetti, falecido em 2005. Declara que seu trabalho caminha na direção das produções deste autor, ao tentar "mergulhar nas práticas, nas imagens e nos valores associados ao mundo das camadas populares, da rua e da vida local (p.15). De fato, essa proximidade é perceptível. Historia social del fútbol [...] compartilha da sensibilidade dos escritos de Archetti, especialmente nos livros "Masculinidades: Fútbol, pólo y tango en Argentina" (2003) e "El potrero, la pista y el ring: las patrias del deporte argentino" (2001).

Sendo assim, um ponto de destaque do livro é sua ênfase nas experiências que constituíram o futebol nos bairros portenhos, locais privilegiados para se explorar, 
Dossiê | As contribuições do livro Historia social del Fútbol: del amateurismo a la profesionalización para os estudos do futebol na América Latina (MAYOR, Sarah Teixeira Soutto)

segundo o autor, a tensão entre as forças homogeneizadoras e fragmentadoras emergentes na sociedade civil. Reafirma-se o compromisso de uma investigação centrada em "aspectos poucos explorados da vida cotidiana e os âmbitos da sociabilidade masculina - como o café, a rua, a esquina - tantos cenários 'tingidos' de futebol" (p.17).

Jornais e revistas foram as principais fontes utilizadas pelo autor, que também se debruçou em materiais institucionais das associações prévias à AFA, em dados censitários e em plantas encontradas no Instituto Histórico da Cidade de Buenos Aires. Em relação aos jornais, alguns exemplos são: La Nación, La Prensa, El Diario, La Argentina, La Mañana, Última Hora e Crítica. Em se tratando das revistas, destacam-se La Cancha e El Gráfico. Sobre a última, fundada em 1919 e ainda em circulação na atualidade, vale mencionar sua importância. Eduardo Archetti (2003), por exemplo, considerava El Gráfico a revista esportiva de maior influência na Argentina e destacava seu grande alcance em outros países do continente.

No intento de localizar um contexto de existência do jogo, Frydenberg problematiza o que denomina de "três vias de advento e desenvolvimento do futebol na cidade". Seriam elas: 1) a via mítica, uma espécie de lenda que atribui o pioneirismo a marinheiros ingleses, mas que carece de fontes verificáveis; 2) a via dos clubes, chamada de "frustrada", que se baseia na primeira partida realizada no país, em 1867, promovida pelos sócios do Buenos Aires Cricket Club, mas que resultou em ações efêmeras; 3) e a via heroica, protagonizada pelas escolas e ligas. Essa última é considerada por Frydenberg a que inaugurou a tradição futebolística da cidade, capitaneada, especialmente, pelas instituições educacionais da colônia inglesa. Destacase a figura do professor escocês Alejandro Watson Hutton, que chegou à Argentina em 1882 e fundou o Buenos Aires English High School, em 1884. O professor teria introduzido o futebol e outras modalidades esportivas no programa escolar, alinhandose às prerrogativas educativas do ensino britânico. O autor constata a apropriação da prática esportiva e dos valores do fair play por outros grupos sociais, como a elite criolla, o que propiciou o surgimento do futebol que se pode chamar de "oficial".

Frydenberg ressalta a ausência da modalidade na vida cotidiana dos setores populares, nos primeiros anos do século XX. Tal afirmação é posteriormente acompanhada da constatação de que, ao final dos anos 1920, o jogo inglês havia se 
Dossiê | As contribuições do livro Historia social del Fútbol: del amateurismo a la profesionalización para os estudos do futebol na América Latina (MAYOR, Sarah Teixeira Soutto)

transformado em espetáculo massivo com estádios cheios e jogadores profissionais: “Em poucos anos o futebol deixou de ser uma novidade para ser considerado um veículo 'natural' de conexão geracional e um 'natural' definidor das atitudes masculinas" (p.18).

Esse curto período guarda particularidades importantes que são essenciais para se compreender o desenvolvimento do futebol argentino. O fato em si - a rápida transformação do jogo em espetáculo - não é uma novidade e possui semelhanças com outros contextos, como o brasileiro. Tampouco seria inesperada a constatação dos primórdios elitistas do esporte. Assim sendo, um dos maiores méritos do trabalho de Frydenberg talvez resida na maneira de olhar para os setores populares, localizando o protagonismo dos jovens nos bairros que se formavam em Buenos Aires. O autor revela não apenas uma apropriação do esporte por um público antes privado de seus códigos distintivos, mas uma ressignificação do jogo em consonância com as próprias transformações geográficas e simbólicas da cidade.

O futebol jogado nas ruas e nos terrenos baldios desenvolvia uma espécie de "sociabilidade masculina", que constituía o imaginário local em meio ao universo dos cafés e dos cortiços, propiciando a mistura entre o criollo e o imigrante e contribuindo paulatinamente para a "argentinização" do jogo. Em suma, não há apenas uma constatação factual de que o futebol foi vivenciado pelas classes populares, mas o desvelamento de como esse esporte, com as suas particularidades, constituiu os imaginários local e nacional ao mesmo tempo em que foi sendo ele mesmo constituído pelas mesclas e tensões que permearam a coexistência das múltiplas identificações que se formavam na cidade em franco desenvolvimento.

Para compreender esse cenário, o livro confere especial atenção à formação dos clubes, das ligas e associações. Com relação às ligas, o autor destaca a tentativa de criação da primeira delas no ano de 1891, por membros das escolas britânicas. No entanto, a então Argentine Association Football League (AAFL) apenas se materializou dois anos mais tarde, filiando-se à Futebol Association (FA) em 1904.

Sobre as equipes, Frydenberg reafirma a soberania inglesa presente no final do século XIX e início do século XX e destaca a predominância das instituições de ensino, 0 que pode ser confirmado por meio de uma ação da AAFL, que determinou que os nomes dos clubes deveriam ser diferentes dos nomes das escolas, a partir de 1900. O clube Alumni, considerado a maior referência deste período, é um exemplo dessa 
Dossiê | As contribuições do livro Historia social del Fútbol: del amateurismo a la profesionalización para os estudos do futebol na América Latina (MAYOR, Sarah Teixeira Soutto)

transformação, pois deriva do antigo Buenos Aires English High School (BAEHS). Seu lema, "esporte pelo esporte", é destacado no livro como símbolo máximo do amadorismo inglês e de suas características distintivas. Condutas relacionadas a comportamentos e valores como honra, retidão, irmandade e afeto com o adversário são enfatizadas como formadoras do universo dos "verdadeiros sportsmen" (p.33).

Em meio ao debate do esporte como potente demarcador de estilos de vida e lugares sociais, emerge no livro a narrativa de um fato curioso. Ao descrever as categorias da Liga, o autor menciona a organização de uma quarta divisão para menores de 17 anos, destinada a estudantes. Ainda em 1904, momento em que o esporte era supostamente sustentado pelos princípios desinteressados do amadorismo, instituiu-se a exigência de apresentação de certidão de nascimento pelos atletas devido à inscrição de jogadores mais velhos de forma fraudulenta. A menção à existência de punição para a utilização de documentos falsos reafirma as ambiguidades que o futebol experimentava à época. O viés competitivo já começava a se sobressair sobre as finalidades morais nos anos iniciais do século XX.

Nessa direção, o autor destaca a reverberação das tensões criadas pelo esporte nas páginas dos periódicos, que indagavam a incompatibilidade dos abrangentes discursos educativos e civilizadores com a restrita realidade que limitava o acesso da maioria da população. Se havia, por um lado, a defesa da ampliação da prática do futebol argumentada pelos seus supostos benefícios educativos (bastante distintos, obviamente, em relação às classes sociais), por outro lado mantinham-se as medidas segregadoras para se adentrar a esse universo. No caso dos clubes que começavam a se expandir, entre as condições mais evidentes e cerceadoras, estava a exigência de campo próprio com vestiário. Como sinaliza Frydenberg (p.37), uma situação paradoxal se criava: "a maioria dos clubes que estava fora da Liga desejava ingressar nela e alguns dos que estavam dentro foram expulsos, sempre em um contexto que ressaltava a necessidade de difundir este esporte".

Os impasses gerados pela questão econômica, no entanto, acabaram sendo catalisadores do que o autor denomina de "argentinização" da Liga, ao fomentarem debates constantes sobre temas relacionados à organização do futebol e confrontarem normas e valores pré-estabelecidos. Em 1907, por exemplo, foi imposto o uso do 
Dossiê | As contribuições do livro Historia social del Fútbol: del amateurismo a la profesionalización para os estudos do futebol na América Latina (MAYOR, Sarah Teixeira Soutto)

castelhano nas reuniões e, em 1912, houve a substituição da palavra "Association" por "Asociación".

O livro também aborda a participação decisiva da imprensa no processo de popularização do futebol e de formação de um público consumidor, ao enfatizar controvérsias que geravam tensão e fomentavam a atração dos leitores. Frydenberg constata o surgimento, no jornal El País, das primeiras crônicas em castelhano sobre partidas de futebol ainda no ano de 1901. No ano de 1903, os impressos La Nación, La Prensa e La Argentina criaram uma seção específica sobre o jogo. Nesse momento, o jornalismo já passava a disputar o lugar de "cátedra" do esporte, reivindicando um espaço próprio nos estádios. Ao narrar essa precoce intervenção, o autor retoma a indagação de como o futebol teria deixado de ser um evento de pouca relevância para se transformar em algo tão atrativo, em tão pouco tempo. Em suas palavras, o futebol havia resultado "imparável" (p.43). Constata que o evento que convocava as personalidades mais influentes da cidade de Buenos Aires nos primeiros anos do século XX passara a congregar mais de 20.000 torcedores nos estádios, no final da segunda década.

Uma das explicações para esse notável alcance reside nas visitas de equipes estrangeiras ao país, em sua maioria inglesas, desde o ano de 1904. Sobre essa particularidade, Frydenberg suscita uma contraditória e importante questão. O sucesso dos jogos das equipes inglesas, que provocavam a curiosidade dos habitantes locais, contrastava com o próprio posicionamento dos principais representantes do futebol nacional, que defendiam a manutenção do formato amador. Ou seja, ao mesmo tempo em que "todos os olhos estavam postos na liga inglesa profissional" enquanto espetáculo, a adoção formal do profissionalismo era repudiada no país (p.41).

Para Frydenberg, a transformação do que era mero entretenimento em atividade dotada de enorme peso e de significativa carga emocional se deu fortemente em razão do caráter simbólico do jogo. O valor de uma partida comportava muito mais do que o resultado da competição esportiva, compreendendo um "compêndio de infinitas eleições morais"; "uma arena onde se colocavam em jogo a honra e a hombridade" (p.83). No caso específico de Buenos Aires, o autor destaca a importância dos cafés e das ruas como construtores dos valores de honra, virilidade e guapeza para os grupos populares que começavam a se apropriar do esporte. A masculinidade do 
Dossiê | As contribuições do livro Historia social del Fútbol: del amateurismo a la profesionalización para os estudos do futebol na América Latina (MAYOR, Sarah Teixeira Soutto)

criollo suburbano estava associada a esses códigos, dos quais se destacava o último. Ser guapo, segundo o autor, equivalia a estar disposto ao enfretamento corporal, à valentia. A honra, aliada à força do guapo, estruturava as distâncias e hierarquias sociais. No caso dos grupos populares, "quase sempre era o único que se possuía e, portanto, recorriase a ela na hora de se exibir e lutava-se para defendê-la" (p.87).

O autor observa que esses jovens que adotaram o futebol em princípios do século XX foram influenciados inicialmente pelas práticas habituais do esporte já desenhadas para eles, com os valores dominantes das instituições que os promoviam. No entanto, foram paulatinamente construindo outras possibilidades, que se distanciavam das práticas e dos valores da liga oficial. O protagonismo desses jovens demarcou a cultura do associacionismo, uma experiência concretizada pela ativa militância em organizações, clubes e ligas independentes. Um forte exemplo foi a criação de "clubes-equipes", ação que demandava menos estrutura e comprometimento financeiro dos participantes, já que se distanciava da ideia de clube tradicional. Na maioria dos casos, os clubes fundados eram equipes de somente onze, doze ou treze jogadores, que dividiam as funções diretivas. Ao contrário da liga oficial, para participar das ligas independentes era necessário apenas o pagamento da cota de ingresso e possuir nome, selo, domicílio postal e cores distintivas.

Dessa forma, uma intensa expansão de clubes na cidade de Buenos Aires foi desencadeada, o que contribuiu para a difusão e popularização do futebol. Nessa perspectiva, Frydenberg conclui que se iniciava um novo sentido de pertencimento grupal, representado pela equipe de futebol, que passava a defender um determinado território. A plasticidade do esporte é destacada como um dos atrativos, por possibilitar uma articulação magistral do "instante e da excepcionalidade do ritual domingueiro com a regularidade e o cotidiano da vida diária", influenciando "eficazmente sobre a construção de identidades territoriais no marco de uma fluida relação entre o espetáculo e o mundo ordinário da vizinhança [...]" (p.130). Para o autor, esses jovens que se apropriaram do jogo à sua maneira, com os códigos e símbolos que lhes faziam sentido de acordo com suas próprias experiências, participaram da construção da cidade mediante a prática e o "fazer do futebol", que também se configurou como uma espécie de sustentação material da rede urbana (p.88). 
Dossiê | As contribuições do livro Historia social del Fútbol: del amateurismo a la profesionalización para os estudos do futebol na América Latina (MAYOR, Sarah Teixeira Soutto)

Frydenberg constata, assim, o desenvolvimento do jogo no conjunto de instituições da sociedade civil e do Estado. Cita as forças armadas, as empresas, a igreja e as associações de trabalhadores, incluindo alguns partidos políticos de esquerda, como exemplos de sua difusão na cidade. A espetacularização do futebol passa a adquirir contornos mais nítidos, especialmente na década de 1920, momento em que o desempenho dos atletas começa a se destacar e a embasar os objetivos do jogo.

O "golondrineo", termo utilizado para designar a passagem de um jogador por várias equipes, é problematizado pelo autor como um dos sintomas da transformação do esporte (p.184). Imersa na lógica do "marronismo", a prática sinalizava a força do mercado que se gestava em torno do futebol, situação que impactava as finalidades e os princípios iniciais do jogo e o transformava em possibilidade de ganho financeiro para os jovens das famílias trabalhadoras. Frydenberg destaca que o "marronismo" esteve associado a fatores como o crescimento do espetáculo com sua lógica mercantil, o "exitismo" e a construção de rivalidades (p.189). Sobre o último fator, o livro traz uma constatação interessante: a deteç̧ão pela imprensa da atuação das "barras bravas" desde meados dos anos 1920. Frydenberg cita uma reportagem do jornal $A$ Crítica, que assim definia os torcedores: “um grupo mais ou menos uniforme de 'energúmenos' que somente vão aos campos com o objetivo de manifestar seus baixos instintos" (p.226).

O exemplo supracitado é um demonstrativo importante do alcance do jogo nas primeiras décadas do século XX. A experiência da rivalidade e o incômodo com a violência já demonstravam o poder que o futebol adquiria como experiência cotidiana e como fator de identificação da masculinidade nos grupos de torcedores. Tamanha modificação nas características e nos propósitos do fenômeno seria decisiva para a regulamentação da profissionalização no ano de 1931. O interessante no caso argentino é sua especificidade no que tange aos protagonistas da legalização do regime. Um movimento dos jogadores em defesa do passe livre contribuiu decisivamente para romper com as últimas amarras do falso amadorismo. Em resposta à implantação de penas mais severas pela Liga para os jogadores que mudavam de clube sem o consentimento da entidade em que jogavam, vários dos principais atletas resolveram deflagrar uma greve, causando enorme impacto nos torneios e na rentabilidade das partidas. A adoção às claras do profissionalismo, em 1931, foi uma das consequências da luta dos jogadores pela liberdade de atuação e exemplifica as disputas que 
Dossiê | As contribuições do livro Historia social del Fútbol: del amateurismo a la profesionalización para os estudos do futebol na América Latina (MAYOR, Sarah Teixeira Soutto)

aconteciam fora do campo, envolvendo interesses que já demarcavam os novos propósitos da diversão tornada espetáculo.

Em linhas gerais, pode-se inferir que a importância adquirida pelos jogadores no formato competitivo e mercantil que se delineava (e que culminou na profissionalização) caminhava passo a passo com a formação dos grupos de torcedores, que passavam a projetar na vitória do clube o seu próprio sucesso. De forma simultânea, o progressivo aumento do número de expectadores também se tornava fator decisivo para a valorização dos jogadores, que poderiam usar de sua popularidade para defender seus objetivos.

Tantos outros pontos poderiam ser aqui elencados para compor a análise de Historia Social del Fútbol [...], um livro rico e de rara qualidade. É, sem dúvidas, uma das principais referências para quem deseja compreender os processos históricos que transformaram, em tão pouco tempo, o restrito "jogo de cavalheiros" em espetáculo massivo, com a notável particularidade de esmiuçar o desenvolvimento e a ressignificação do esporte no universo dos setores populares e sua importância na construção identitária da masculinidade criolla. Ainda que aborde o cenário bonaerense e a especificidade de seus bairros, cortiços, cafés, terrenos baldios, redes de transporte, clubes, campos e estádios, a pesquisa de Frydenberg se revela valiosa para a problematização de outros contextos latino-americanos, entre eles o brasileiro. 0 descortinamento de elementos que se aproximam em meio às especificidades de cada país ou cidade acaba por se tornar um contributo importante para a expansão dos olhares sobre o jogo enquanto fenômeno social e relacional.

De uma maneira geral, pode-se dizer que o trabalho combina o rigor científico com a leveza de uma narrativa agradável e acessível e, desta forma, o leitor é presenteado com um livro que pode ser lido e apreciado como obra literária, ainda que seu principal intuito seja o acadêmico. Fica, então, o convite à leitura.

\section{Referências}

ARCHETTI, Eduardo. El potrero, la pista y el ring: las patrias del deporte argentino. Cidade do México: Fondo de Cultura Económica, 2001.

Antropofagia, 2003. . Masculinidades. Fútbol, tango y polo en la Argentina. Buenos Aires: 